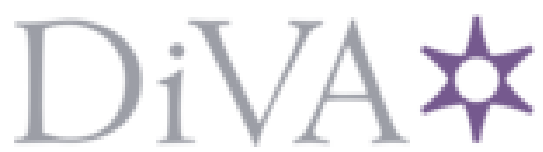

http://www.diva-portal.org

This is the published version of a paper published in .

Citation for the original published paper (version of record):

Elleström, L. (2018)

Identifying, Construing, and Bridging over Media Borders

Scripta Uniandrade, 16(3): 15-30

Access to the published version may require subscription.

N.B. When citing this work, cite the original published paper.

Permanent link to this version:

http://urn.kb.se/resolve?urn=urn:nbn:se:lnu:diva-79396 


\title{
Identifying, Construing, and Bridging over Media Borders ${ }^{1}$
}

\author{
LARS ELLESTRÖM, PhD \\ Linnaeus University, Suécia \\ lars.ellestrom@lnu.se
}

\begin{abstract}
The article will center on the necessary but always problematic notion of media borders, which has since long been scrutinized by intermedial studies. My initial observation is that it is impossible to navigate in one's material and mental surrounding if one does not categorize objects and phenomena; without categorizations everything would be a blur - difficult to grasp and to explain. However, categorization requires borders, and borders can and should always be disputed. The area of communication is not an exception: on one hand it is necessary to somehow categorize media into types, and on the other hand it is not evident how these categorizations should be made. My aim is not to argue in favor of or against certain ways of classifying communicative media, but to try to explain some of the functions and limitations of media borders. I argue, in brief, that there are different types of media borders and hence different types of media types; if these differences are not recognized, the understanding of media categorization will remain confused. Whereas some media borders are relatively stable, others are more subject to change; therefore, media borders can be understood to be both identified and construed. However, in the end virtually all media borders can be bridged over through our cross-modal cognitive capacities.
\end{abstract}

Keywords: Media Borders. Media Types. Categorization. Intermediality. Multimodality. Cross-modality. Iconicity.

Autor convidado.

\footnotetext{
${ }^{1}$ Palestra profeerida no X Seminário de Pesquisa e II Encontro Internacional da UNIANDRADE e VII Jornada Intermídia.

ELLESTRÖM, Lars. Identifying, Construing, and Bridging over Media Borders. Scripta Uniandrade, v. 16, n. 3 (2018), p. 15-30.

Curitiba, Paraná, Brasil

Data de edição: 11 nov. 2018.
} 


\section{Identificando, construindo e transpondo} fronteiras midiáticas

RESUMO: Este artigo versa sobre a noção necessária, mas sempre problemática, das fronteiras das mídias que desde longa data têm sido investigada pelos estudos intermidiáticos, constituindo-se em tema central de minha pesquisa. Minha observação inicial é a impossibilidade de navegar no ambiente material e mental circundante sem a categorização de objetos e fenômenos; se não houvesse categorização tudo se tornaria confuso - dificil de entender e explicar. No entanto, a categorização requer zonas fronteiriças - e essas fronteiras podem e deverão sempre ser postas em questão. A área de comunicação não é uma exceção: por um lado, é necessário categorizar a mídia em tipos e, por outro, não há clareza como essas categorizações devem ser feitas. Meu objetivo não é argumentar a favor ou contra certas formas de classificar mídias comunicativas, mas tentar explicar algumas das funções e limitações das fronteiras das mídias. Argumento, resumidamente, que existem diferentes tipos de fronteiras de mídia e, portanto, variedades diferentes de tipos de mídias. Se essas diferenças não forem reconhecidas, a compreensão da categorização das mídias permanecerá ininteligivel. Enquanto algumas fronteiras de mídias são relativamente estáveis, outras são mais sujeitas a mudanças; portanto, as fronteiras de mídia podem ser entendidas como instituídas e construídas. No entanto, no final, virtualmente todas as fronteiras das mídias podem ser ultrapassadas por meio de nossas capacidades cognitivas transmodais.

Palavras-chave: Fronteiras de mídias. Tipos de mídias. Categorização. Intermidialidade. Multimodalidade. Transmodalidade. Iconicidade.

This article will center on the necessary but always problematic notion of media borders, which has since long been scrutinized by intermedial studies and is also central for my own research. It is not my aim to argue in favor of or against certain ways of classifying communicative media. Rather, I will try to explain some of the functions and limitations of media borders and discuss the relativity of categorizing media. I will attach to concepts that I started to examine already a decade ago but also include refinements and recently developed ideas concerning the nature of 
media and their interrelations. I will start with some discussions of the inevitability of categorizing media through media borders, continue with an overview of different types of media borders, and conclude with an explanation of how media borders can be bridged over.

\section{Categorizing Media through Media Borders}

It is virtually impossible to navigate in one's material and mental surrounding if one does not categorize objects and phenomena; otherwise everything would be a blur difficult to grasp and to explain. However, categorization requires borders - or at least border zones - and borders can and should always be disputed. The area of communication is not an exception: on one hand it is necessary to somehow categorize media into types, and on the other hand it is not evident how these categorizations should be made.

\section{Media Products}

What is then categorized in communication? I suggest that a central element for categorization in the broad area of communication is the media product understood as a single entity in contrast to types of media. When referring to "a talk" one refers so a specific media product - or, in Irina Rajewsky's terminology, a "medial configuration" (2010) - and when referring to "talk" one rather refers to a type of medium.

My suggestion is to use the term "media product" to denote the intermediate stage that enables transfer of cognitive import, or "meaning", from a producer's mind to a perceiver's mind (Elleström 2018). Media products may be realized by either nonbodily or bodily matter (including matter emanating directly from a body), or a combination of these. This means that the producer's mind may, for instance, use either non-bodily matter (such as the paper of a written letter) or her own body and its immediate extensions (such as speech and gestures) to realize media products. Furthermore, the perceiver's body may be used to mediate media products; for instance, the producer may realize a painting on the perceiver's skin or push her/him gently to communicate the desire that she/he move a bit. Additionally, other bodies, such as the bodies of actors, may be used as media products. In contrast to influential scholars such as Marshall McLuhan who conceptualize media as the "extensions of man" in general (1994 [1964]), I thus define media products as "extensions of mind" in the context of inter-human communication.

Since being a media product should be understood as a function rather than an essential property, virtually any material existence can be used as one, including not only solid objects but all kinds of physical phenomena that can be perceived by 
the human senses. In addition to those forms of media products that are more commonly categorized as such (written texts, songs, scientific diagrams, warning cries, road signs, etc.), there is an endless row of forms of physical objects, phenomena, and actions that can function as media products given that they are perceived in situations and surroundings that encourage interpretation in terms of communication. These include nudges, blinkings, coughs, meals, ceremonies, decorations, clothes, hair styles, and make-up. Also, dogs, wine bottles, and cars of certain breeds, brands, and designs may well function as media products to communicate the embracing of certain values or simply wealth, for instance. Within the framework of a trial, both the footage from surveillance cameras and spoken words from witnesses function as media products as well as fingerprints, DNA samples, and blood stains presented by the prosecutor.

Thus, there is no such thing as a media product "as such". Not even a written text is a media product in itself, I argue; it is only when its function of transferring cognitive import among minds is realized that it can be conceptualized as a media product. The archaeologist who inspects the marks on a bone and believes that they are caused by accidental scraping is not involved in communication. If the archaeologist believes that the marks are some sort of letters in an unknown language, the archaeologist may well be engaged in elementary communication to the extent that a communicative intent is understood. If the marks are eventually deciphered, more complex communication may result. If the deciphering turns out to be mistaken, the belief that communication occurred is an illusion. Border cases like these could of course be exemplified also by everyday interaction among people who may or may not be mistaken about the significance of all kinds of movements, glances, and sounds.

Given this conceptualization, it is pointless to try to distinguish between physical existences that are and that are not actual media products. What is important is rather to have a clear notion of the properties of physical existences that confer the function of media products on them. These properties are in no way self-evidently present. Perceiving something as a media product is a question of being attentive to certain kinds of phenomena in the world. As humans have been able to communicate with each other for thousands and thousands of years, this attention is partly passed on by heredity, but it is also deeply formed by cultural factors and the experience of navigating within one's present surroundings. Knowledge of musical performance traditions, for example, leads to specific attention to certain details while others may be ignored; thus, accidental noises and random gestures may be sifted out as irrelevant for the musical communication and not part of the media product.

More practical knowledge of the environment normally makes us pay attention to what happens on the screen of a television set rather than to its back side. If the 
television set is used in an artistic installation, however, or if a repairman tries to explain why it does not work by way of pointing to certain gadgets, it may well be the back side that should be selected for attention in order to achieve the function of a media product. Media products must thus often be understood as cultural entities that are very much dependent on social praxis. They are formed by (often shared) selective attention on sensorially perceptible areas that are believed to be relevant for achieving communication.

\section{Media Modalities}

In spite of the complex nature of media products it is of course fully possible to categorize them in various ways. A discussion of media categorization requires proper attention to the basic qualities of media products, understood as physical intermediate entities that enable transfer of cognitive import, or "meaning", between at least two minds. This involves qualities that must be understood as situated within the range from the purely material to the purely mental; qualities that involve physical properties as well as cognitive processes. I have suggested that the concept of media modalities might be helpful for understanding these qualities and their interrelations (Elleström 2010). This concept is useful also for explaining basic media borders and hence media categorization. I will therefore here present its contours.

I suggest that all media products, without exception, can be analyzed in terms of four kinds of basic traits - or, in other words, four media modalities. Three of these modalities are pre-semiotic, which means that they cover media traits that are involved in signification - the creation of cognitive import in the perceiver's mind although they are not semiotic qualities in themselves. The three modalities are thus not $a$-semiotic; they are pre-semiotic, meaning that the traits that they cover are bound to become part of the semiotic as soon as communication is established. The pre-semiotic traits concern the fundamentals of mediation, which is to say that they are necessary conditions for any media product to be realized in the outer world, and hence for any communication to be brought about.

The three pre-semiotic media modalities are the material modality, the spatiotemporal modality, and the sensorial modality. Media products are all material in the plain sense that they may be, for instance, solid or non-solid, or organic or inorganic, and comparable traits like these belong to the material modality. It is also the case that all media products have spatiotemporal traits, which means that such products that do not have at least either spatial or temporal extension are inconceivable; hence, the spatiotemporal modality consists of comparable media traits such as temporality, stasis, two-dimensional spatiality, and three-dimensional spatiality. Furthermore, media products must reach the mind through at least one sense; hence, sensory perception is the common 
denominator of the media traits belonging to the sensorial modality - media products may be visual, auditory, tactile, and so forth.

The fourth media modality is the semiotic modality that covers media traits concerning representation rather than mediation. Whereas the semiotic traits of a media product are less palpable than the pre-semiotic ones, and in fact are entirely derived from them (because different kinds of mediation have different kinds of semiotic potential), they are equally essential for realizing communication. The mediated sensory configurations of a media product do not transfer any cognitive import until the perceiver's mind comprehends them as signs. In other words, the sensations are meaningless until they are understood to represent something through unconscious or conscious interpretation. This is to say that all objects and phenomena that act as media products have semiotic traits by definition.

By far the most successful effort to define the basic ways to create sense in terms of signs is Charles Sanders Peirce's foundational trichotomy icon, index, and symbol. These three basic sign types are defined on the ground of the relationship between representing and represented entities and can be understood as fundamental cognitive abilities. Icons stand for (represent) their (mental or material) objects based on similarity; indexes do so based on contiguity; and symbols rely on habits or conventions (Peirce 1932, CP2.247-249 [c.1903]; Elleström 2014a: 98-113). I take iconicity, indexicality, and symbolicity to be the main media traits within the semiotic modality, which is to say that no communication occurs unless cognitive import is created through at least one of the three sign types (icons, indexes, and symbols).

As with pre-semiotic traits, the semiotic traits of a media product offer certain possibilities and set some restrictions. Obviously, cognitive import of any sort cannot be freely created on the basis of just any sign type. For instance, the iconic signs of music can represent complex feelings and motional structures that are probably largely inaccessible to the symbolic signs of written text; conversely, written symbolic signs can represent arguments and the appearance of visual objects with much greater accuracy compared to auditory icons. Flagrant examples like these are only the tip of the iceberg in terms of the (in)capacities of signs based on similarity, contiguity, and habits or conventions, respectively. Therefore, communicative transfer of cognitive import through a media product is made possible - but also profoundly limited - by the semiotic traits of the medium.

The basic traits of media products can thus in some detail be mapped with the aid of the conceptual framework of media modalities. Each media product is realized through a specific combination of modes of the modalities; a media product may be, for instance, solid, two-dimensional, visual, and iconic. This means that various media products very often, in a multitude of different ways, share basic media traits, or modality modes, with other media products. The concept of media 
modalities thus partly supports ideas about media always containing other media (McLuhan 1994 [1964]: 8, 305), or media always being mixed media (Mitchell 2005: $257,260)$. However, media are mixed in very different ways. Although the concept of media modalities accounts for a central aspect of how media are entangled in each other, it also illuminates that media are sometimes not really contained by or mixed with other media.

It must also be noted that media products are often more or less multimodal on the level of at least some of the four modalities, meaning that they in some respect include, for instance, both the visual and the auditory mode, both the iconic and the symbolic mode, or both the spatial and the temporal mode. My concept of multimodality is thus more specific than the one used in so called social semiotics (Kress and van Leeuwen 2001) and includes material, spatiotemporal, sensorial, and semiotic multimodality. I think it is fair to say that all media are multimodal as far as the semiotic modality is concerned, whereas some media types, such as computer games and theatre, are multimodal on the level of all four modalities.

\section{Two Different Types of Media Borders}

In the end, each media product is unique. However, thinking species such as humans are in dire need of categorizing things; otherwise we would not be able to navigate in the world or communicate efficiently. Thus we also categorize media products, and as is often the case with classification in general, our media categories are commonly quite fluid. Nonetheless, thinking in terms of media modalities is helpful for understanding media differences and similarities and hence for understanding how fundamental media borders can be established. This is not the whole story, though. Some categorizations are more solid and stable than others because they depend on partly dissimilar factors. There are simply different types of media borders and therefore different types of media categories.

\section{Basic and Qualified Media Types}

That is why I find it helpful to work with the two complementary notions of basic media types and qualified media types (Elleström 2010). Sometimes we mainly pay attention to the most basic features of media products and classify them according to their most salient material, spatiotemporal, sensorial, and semiotic properties. We think, for instance, in terms of still images (most often understood as tangible, flat, static, visual, and iconic media products). This is what I call a basic medium (a basic type of media product) and it is relatively solid because of its perennial fundamental traits.

However, such a basic classification is sometimes not enough to capture more specific media properties. What we do then is to qualify the definition of the media 
type that we are after and add criteria that lie beyond the basic media modalities; we also include all kinds of aspects on how the media products are produced, situated, used and evaluated in the world. We tend to talk about a media type as something that has certain functions or begins to be used in a certain way at a certain time and in a certain cultural and social context. We may want to delimit the focus to still images that, say, are handmade by very young persons - children's drawings. This is what I call a qualified medium (a qualified type of media product) and it is more fluid than the basic medium of still image simply because the added specific criteria are vaguer than those captured by the media modalities. For instance, it may be difficult to agree upon what a handmade drawing actually is: should drawings made on computers or scribble on the wall be included? And when is a child not a child any longer but rather a young adult? The notion of childhood varies significantly among cultures and also changes over time, not to mention the individual differences in maturity. The limits of qualified media are thus bound to be ambivalent, debated, and changed much more than the limits of basic media.

Qualified media types include categories such as music, painting, television programs, news articles, visual art, Morse messages, sign language, and email. Although they are normally construed on the ground of one or several basic media types, and therefore may have certain stability, the qualifying aspects are, of course, not eternally inscribed but formed by conventions (cf. Wolf's definition of a medium as "a conventionally distinct means of communication, specified not only by particular channels [or one channel] of communication but also the use of one or more semiotic systems serving for the transmission of cultural 'messages" [1999: 35-36]).

In brief, then: Media types that are mainly identified by their modal appearances I call basic media types. The classification of basic media types is relatively stable. Culturally shaped media types such as art forms that rely also on qualifying aspects I call qualified media types. The classification of qualified media types is relatively unstable. This is to say that media borders can be stronger and weaker or, in other words: media borders can be understood to be both identified and construed. If this difference is not recognized, the understanding of media categorization will remain confused.

\section{Intermedial Relations in a Narrow and a Broad Sense}

From this distinction between at least two different types of media borders it follows that intermedial relations can be understood in at least two different ways. Thinking of intermedial relations in a narrow and a broad sense is useful for disentangling the intricate notion of crossing media borders. 
Intermedial relations in a narrow sense means relations among dissimilar basic media types (or among media products belonging to dissimilar basic media types) that is, relations among media types based on different modality modes. This involves transgressing relatively strong media borders when moving between them.

Intermedial relations in a broad sense means relations among dissimilar qualitied media types (or among media products belonging to dissimilar qualified media types) in those cases where no differences in modality modes are present. Several qualified media types are based on the same modality modes; consequently, they belong to the same basic media type and their interrelations are intermedial only in a broad sense. This involves transgressing relatively weak media borders when moving between them. For instance, the two media types written poetry and scholarly article are qualified in very different ways, although they are both typically understood to consist of visual, static, and symbolic signs that are sequentially decoded from a flat surface. Whereas the interrelation between poetry and scholarly article is intermedial in a broad sense, it is not intermedial in a narrow sense. Sections of poetry can be incorporated in scholarly articles (and vice versa) relatively seamlessly, without modifying modality modes.

Intermedial relations in a narrow sense are thus to a large extent a question of "finding" or identifying media borders between basic media types. Intermedial relations in a broad sense are more a question about "inventing" or construing media borders between qualified media types.

\section{Bridging over Media Borders}

Crossing media borders might be understood as the phenomenon that one particular media product can be classified in different ways. A certain threedimensional, solid artifact may for instance be categorized both as an artistic sculpture and an object for religious adoration, which means that it in a broad sense bridges over qualified media borders. This is possible because the processes of qualifying media products are largely open-ended, overlapping, and changing.

\section{Cross-Modal Cognitive Capacities}

However, I here want to emphasize some fundamental cognitive capacities that explain how basic media borders can be bridged over in a narrow sense: crossmodal cognitive capacities. In the end, virtually all media borders can be bridged over to some extent, although certainly not completely, through our cross-modal 
cognitive capacities. They are thus fundamental for understanding all forms of intermedial relations.

The term "cross-modal" can be used in various ways. In the context of communication it usually refers to connections among the senses. However, in line with the concept of media modalities, "cross-modal" for me refers to the crossing of all forms of pre-semiotic modes.

More specifically, then, cross-modality should here be understood as cross-material, cross-spatiotemporal, and cross-sensorial representation through iconicity, indexicality, or symbolicity. For instance, solid media products may represent nonsolid objects, static media products may represent temporal objects, and auditory media products may represent visual objects - through iconicity, indexicality, or symbolicity. Hence, different types of basic media can partly represent the same (mental or material) objects. The idea of a running dog, for instance, a solid, organic, spatiotemporal, and largely visual object, can be represented by a variety of different basic media types - not only solid, organic, spatiotemporal, and visual media. This is what I mean when I state that basic media borders can be bridged over through cross-modal cognitive capacities: our minds are to some extent capable of leaping from mode to mode in the act of representation.

Initially, my account of material, spatiotemporal, and sensorial modes had the purpose of clarifying basic properties of media products. However, as just demonstrated, it is clear that these modes may also be used to characterize the objects of media products - what they represent, what they call forth in the mind of the perceiver. While represented objects such as abstract concepts may have an almost purely cognitive character, objects that are made present to the mind in signification may also be more or less concrete and physical. A painting of a face represents a face because the features of the painting are similar to the features of actual, physical faces as they are stored as recollections in our minds (Elleström 2014a). Hence, media products have certain material, spatiotemporal, and sensorial traits, and by the same token the objects that they represent iconically, indexically, or symbolically may have either the same or other material, spatiotemporal, and sensorial traits - or they may have a cognitive nature.

The cross-modal capacities of our minds thus make a certain range of cross-modal representation possible. It may be iconic, indexical, or symbolic representation. I will here demonstrate the phenomenon through the example of cross-modal iconicity. This entails added emphasis on some semiotic key concepts elaborated by Peirce. 


\section{Example: Cross-Modal Iconicity}

Iconicity should be understood as the perception of mental or material entities as representations of objects through similarity, which requires certain cognitive abilities. Much iconicity is mono-modal, meaning that the sign or representamen "something which stands to somebody for something in some respect or capacity" (Peirce 1932, CP2.228 [c.1897]) - calls forth an object in the mind that is of the same kind as the representamen (such as something visual representing something visual because of a perceived similarity). However, there is also cross-modal iconicity (such as something visual representing something auditory because of a perceived cross-modal similarity).

Cross-modal iconicity is iconicity that crosses the borders of different kinds of material, spatiotemporal, and sensorial modes - and between sensory structures and cognitive configurations (Elleström 2017). For instance, a two-dimensional sign, or representamen, may stand for a three-dimensional object (most photographs are taken to represent space including depth), and a visual representamen may stand for an auditory object (the dots and lines in a Morse message may represent short and long beeps). This is because our mind, to a certain extent, has the ability to perceive resemblances not only within the same but also across different sensory areas and different mental realms. I suggest that what is generally called metaphor is essentially complex cross-modal iconicity, or iconicity crossing the borders of cognitive domains.

Although there is much debate on exactly why and how cross-modal phenomena arise, there is a large body of research clearly demonstrating their global existence (see Spence 2011 for an extensive overview and Elleström 2017 for further references and examples). In what follows, I will present a small selection of crossmodal iconic representation.

Cross-material iconicity. One example of cross-material iconicity is the materially solid lines in a printed comic strip representing iconically non-solid wind blowing. A drawing consisting of inorganic materiality may furthermore depict an organically material entity such as a flower. A sculpture consisting of lifeless stone may represent, through resemblance, a living human body; conversely, when playing charades, a living human body may represent iconically a lifeless stone. Another example of cross-material iconicity is a materially solid, inorganic photograph depicting a liquid such as water and an organic human body (Figure 1). 


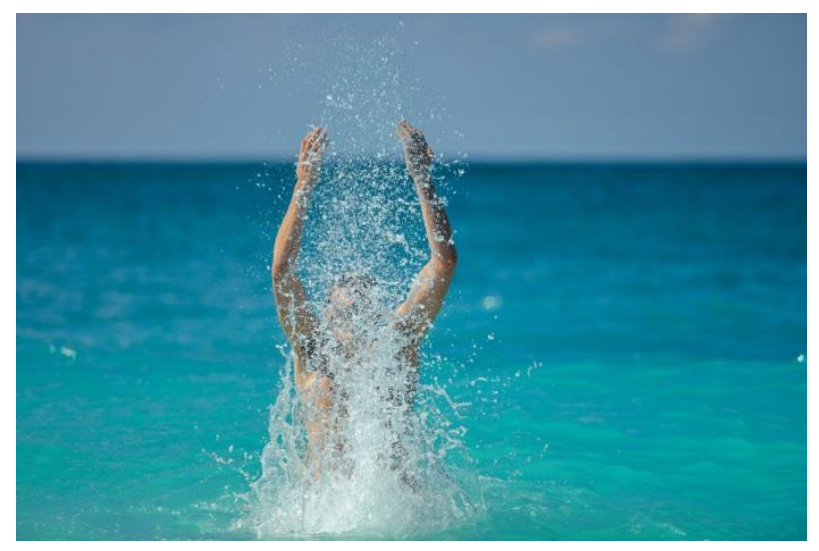

Fig. 1. Photograph of person in water

Cross-spatiotemporal iconicity. The same photograph (Figure 1) may be used to illustrate spatiotemporal crossings in iconicity: a two-dimensional, static representamen stands for a three-dimensional, temporal object. As the person in the represented sphere of the photograph is not likely to be understood as surrounded by immobile, flat water drops, it is almost unavoidable to add a third spatial dimension and time. In spite of its restricted two-dimensionality, the photograph thus resembles a scene from a four-dimensional world.

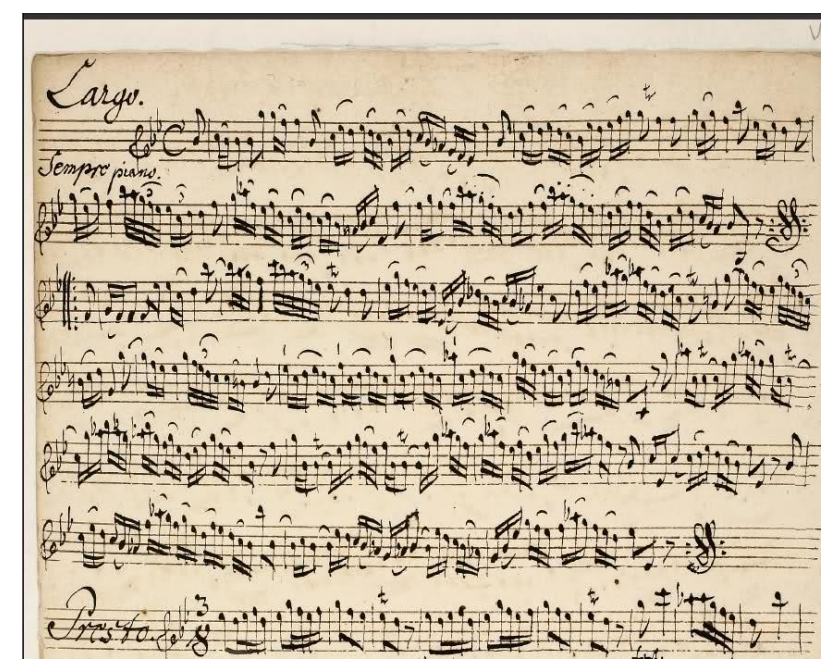

Fig. 2. A score sheet by Johann Sebastian Bach 
A musical score by Johann Sebastian Bach (Figure 2) might serve as another example of cross-spatiotemporal iconicity, although it is clear to see that it partly makes its work with the aid of symbols: it is a two-dimensional and static representamen depicting a temporal object, sounding music (which no doubt also has certain three-dimensional spatial qualities). Likewise, a two-dimensionally spatial but non-temporal representamen such as a chart diagram may represent a temporal phenomenon such as increasing global temperature in the atmosphere.

It must be noted that it is not always the case that less complex representamens stand for more complex objects, such as a two-dimensional movie screen representing a three-dimensional world. It may also be the other way round; a three-dimensional tableau vivant may well depict a two-dimensional painting (which in its turn, of course, may represent a three-dimensional world). All in all, the distinction between different spatiotemporal modes, like the distinction between different material modes, reveals not only typical differences between media types, but also the ability of iconicity to cross these borders.

Cross-sensorial/cognitive iconicity. The Bach score (Figure 2) is also an illustration of cross-sensorial iconicity; a visual representamen that stands for an auditory object - sounding music. Another example is the well documented iconic relation on the one hand between high or front vowels, proximity, and small size, and on the other hand between lower or back vowels, distance, and large size (Anderson 1998: 212). This is sound representing phenomena that are visual but also to some extent haptic. The field of cross-sensorial iconicity is rich and includes media products with clearly indexical elements. With the aid of a thermocamera, for instance, one can create visual icons of objects that are sensed through their heat. Interestingly, iconicity can also cross the borders between actual human senses and senses that only other animals have - or between actual and purely hypothetical senses. Visual icons may represent formations of ultraviolet light that can be seen by bumblebees but not by us. As this kind of light is spread out in a spatial field in a way similar to ordinary light, ultraviolet photography aids us to understand roughly how it would be to actually perceive ultraviolet light. Modern representations of outer space also make it clear that visual surfaces can be used to represent, through similarity, physical phenomena such as extreme types of electromagnetic radiation - physical phenomena that cannot be perceived by any sensory organs at all but can be registered by sophisticated instruments. 


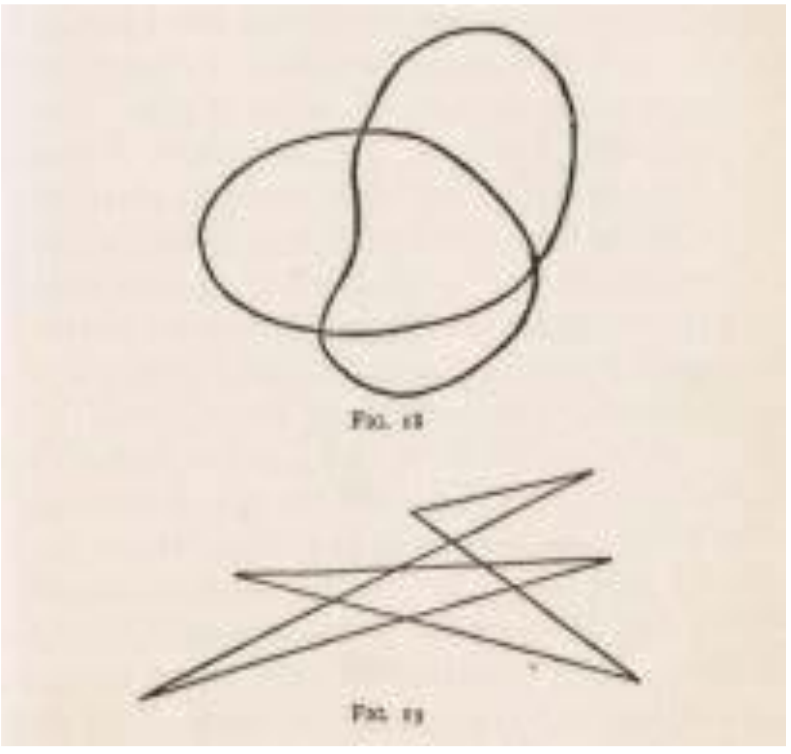

Fig. 3. 'Maluma' and 'takete' (Köhler 1929: 242)

Visual and auditory interconnections probably form the most investigated crosssensorial area. Already in the early twentieth century, influential Gestalt psychologist Wolfgang Köhler argued that there are certain similarities among experiences through different sense organs (1929: 242). He introduced the famous "maluma" and "takete" shapes (Figure 3), illustrating our strong tendency to perceive similarities between the sound of the nonsense word maluma and rounded visual shapes, and between the sound of the nonsense word takete and angular shapes. Since then, these words and shapes have been used in several variations for innumerable empirical verifications of perceived similarities between auditory and visual forms - across different cultures and languages.

It must be noted that there is also research on correspondences between sensory perceptions and cognitive categories. Early investigations indicated that moods (called forth either by music or by words) clearly parallel certain colors (Odbert, Karwoski, and Eckerson 1942). Cross-modal iconicity should hence be understood to include crossing between sensory perception and the more purely cognitive domain. For instance, a visual chart diagram may depict not only concrete phenomena like fluctuation of heat but also abstract phenomena such as economical inflation. By the same token, auditory forms in music may depict mental motions such as experiences and feelings. With this, one is only a short step from iconicity where both representamen and object have a cognitive nature. This is often called metaphoric thinking. 


\section{Media Transformations}

All these cross-modal cognitive capacities, making cross-modal representation possible, can be said to weaken the basic media borders. Although basic media types are dissimilar in relatively stable ways, they all carry the seeds of partly bridging over these dissimilarities. This means, more specifically, that media transformations are possible thanks to the cross-modal capacities: to some extent, and certainly not without consequences, media may represent other media types and represented objects may be transmediated among different media types meaning that they may be represented again by other media types (Elleström 2014b). Given the brain's cross-modal capacities, media representation and transmediation over basic media borders are, within certain frames, possible, common, and indeed productive. Without these capacities, everyday communication would not work at all and artistic phenomena such as ekphrasis and adaptation would certainly not exist.

\section{References}

Anderson, E. R. 1998. A Grammar of Iconism. Madison/Teaneck: Farleigh Dickinson University Press.

Elleström, L. 2010. "The modalities of media: A model for understanding intermedial relations". In Media Borders, Multimodality and Intermediality, ed. L. Elleström, 11-48. Basingstoke: Palgrave Macmillan.

Elleström, L. 2014a. "Material and mental representation: Peirce adapted to the study of media and arts". The American Journal of Semiotics 30: 83-138.

Elleström, L. 2014b. Media Transformation: The Transfer of Media Characteristics among Media. Basingstoke: Palgrave Macmillan.

Elleström, L. 2017. "Bridging the gap between image and metaphor through crossmodal iconicity: An interdisciplinary model". In Dimensions of Iconicity: Iconicity in Language and Literature 15, ed. A. Zirker, M. Bauer, O. Fischer, and C. Ljungberg, 167-190. Amsterdam and Philadelphia: John Benjamins.

Elleström, L. 2018. "Modelling human communication: Mediality and semiotics". In Meanings \& Co.: The Interdisciplinarity of Communication, Semiotics and Multimodality, ed. A. Olteanu, A. Stables, and D. Borțun, 7-32. Cham: Springer.

Köhler, W. 1929. Gestalt Psychology. New York: Horace Liveright.

Kress, G. and T. van Leeuwen. 2001. Multimodal Discourse: The Modes and Media of Contemporary Communication. London: Hodder Arnold. 
McLuhan, M. 1994 [1964]. Understanding Media: The Extensions of Man. Cambridge, MA and London: MIT Press.

Mitchell, W. J. T. 2005. "There are no visual media". Journal of Visual Culture 4: 257-266.

Odbert, H. S., T. F. Karwoski, and A. B. Eckerson. 1942. "Studies in synesthetic thinking: I. Musical and verbal associations of color and mood". Journal of General Psychology 26: 153-173.

Peirce, C. S. 1932. The Collected Papers of Charles Sanders Peirce, vol. 2, ed. C. Hartshorne and P. Weiss. Cambridge, MA: Harvard University Press.

Rajewsky, I. O. 2010. "Border talks: The problematic status of media borders in the current debate about intermediality". In Media Borders, Multimodality and Intermediality, ed. L. Elleström, 51-68. Basingstoke: Palgrave Macmillan.

Spence, C. 2011. "Crossmodal correspondences: A tutorial review". Attention, Perception, \& Psychophysics 73: 971-995.

Wolf, W. 1999. The Musicalization of Fiction: A Study in the Theory and History of Intermediality. Amsterdam and Atlanta, GA: Rodopi.

LARS ELLESTRÖM nasceu na Suécia, em 1960. É professor de Literatura Comparada na Universidade Linnaeus desde 2005 (onde preside o Centro de Estudos de Inter e Multimodalidades) e professor de várias disciplinas no International Society for Intermedial Studies. Seus principais trabalhos são: On Interpreting Literature, Music, and the Visual Arts Ironically (2002), Media Borders, Multimodality and Intermidiality (2010), e Media Transformation: The Transfer of Media Characteristics among Media (2014). Seu trabalho é de fundamental importância para a constituição de modelos teóricos que objetivam a compreensão e a análise das interrelações entre diferentes mídias. 